\title{
Dona Antonieta e os significados de uma vida como diretora do Ginásio de São Roque: uma perspectiva Weberiana
}

\section{Dona Antonieta and the meanings of a life as director of the São Roque High School: a Weberian perspective}

\author{
Doña Antonieta y los significados de una vida \\ como directora del Gimnasio de São Roque: una \\ perspectiva Weberiana
}

Tarina Unzer Lenk ${ }^{1}$

Wilson Sandano ${ }^{1}$

DOI: http://dx.doi.org/10.20435/serie-estudos.v25i54.1426

\begin{abstract}
Resumo: Este trabalho tem como objetivo a compreensão das ações sociais desempenhadas por Antonieta de Araújo Cunha, que atuou por mais de duas décadas na educação secundária da cidade de São Roque, SP, e na construção e direção do ginásio da cidade. Para compreender essas ações sociais, foi utilizada uma abordagem qualitativa da metodologia de história oral, tendo como base a história oral temática, tendo sido realizadas cinco entrevistas semiestruturadas com pessoas que tiveram convivência direta com a diretora ao longo do período em que ela atuou na administração da escola. O referencial teórico adotado nesta pesquisa foi a Sociologia Compreensiva de Max Weber, que fundamentou a compreensão da conduta humana dotada de sentido. Conclui-se que os significados vinculados às ações sociais executadas pela diretora Antonieta se sintetizam em categorias baseadas em valores de ordem, controle, autoridade, obediência e padrões estéticos e higiênicos, ainda presentes no imaginário social da comunidade local de São Roque.
\end{abstract}

Palavras-chave: gestão escolar; Ginásio de São Roque; valores.

Abstract: This paper aims to understand the social actions carried out by Antonieta de Araújo Cunha, who singled out for more than two decades the secondary education of the city of São Roque, SP, building and directing the referred São Roque High School. To understand these social actions, we used a qualitative research approach, which was based upon oral history method, focused on oral history thematic, with five semi-structured interviews with people who had closed relation and proximity with the referred director Antonieta, during the period in which she worked

${ }^{1}$ Universidade de Sorocaba (UNISO), Sorocaba, São Paulo, Brasil. 
in the school administration. The theoretical framework adopted in this paper was upon Max Weber's Comprehensive Sociology, whose essential understanding is about human conduct with meaning. In conclusion, the meanings related to social actions performed by director Antonieta were summarized in categories based on values of order, control, authority, obedience, and aesthetic and hygienic standards, still present in the community of São Roque social imaginary.

Keywords: school administration; São Roque High School; values.

Resumen: Este trabajo tiene como objetivo comprender las acciones sociales realizadas por Antonieta de Araújo Cunha, quien ha trabajado durante más de dos décadas en la educación secundaria de la ciudad de São Roque, SP, y en la construcción y dirección del Gimnasio de la ciudad. Para comprender estas acciones sociales, se utilizó un enfoque cualitativo de la metodología de la historia oral, basada en la historia oral temática, con cinco entrevistas semiestructuradas con personas que tuvieron contacto directo con la directora durante el período en que ella trabajó en la administración de la escuela. El marco teórico adoptado en esta investigación fue la Sociología Comprensiva de Max Weber, que fundó la comprensión de la conducta humana dotada de significado. Se concluye que los significados vinculados a las acciones sociales realizadas por la directora Antonieta se sintetizan en categorías basadas en valores de orden, control, autoridad, obediencia y estándares estéticos e higiénicos, aún presentes en el imaginario social de la comunidad local de São Roque.

Palabras clave: gestión escolar; Gimnasio de São Roque; valores.

\section{INTRODUÇÃO}

Ao resgatar a história do Ginásio de São Roque, foi possível perceber a existência da relação dessa escola com a vida e as formas de ação de Antonieta de Araújo Cunha. Sua história familiar, a formação em Escola Normal, superior em Pedagogia e especialização em Educação Sanitária contribuíram para reforçar seu caráter e a importância de valores morais, de ordem e higiênicos realizados enquanto na direção daquela instituição. As experiências profissionais passadas como professora e diretora foram relevantes para sua atuação no Ginásio de São Roque a partir de 1958.

Ela permaneceu por vinte e quatro anos como diretora do Ginásio de São Roque, desempenhando ações consideradas como paradigmáticas no processo educacional da cidade. Os atos de estruturação, manutenção e preservação da escola, com a criação da Escola Normal e o Instituto de Educação, contribuíram para uma imagem carregada de significados e um mito de personalidade forte, atuante e controversa.

Para entender as atribuições de significados para a diretora, escolheu-se para o desenvolvimento e análise deste trabalho o referencial teórico de Max Weber 
$(1989,1994)$, que tem como fundamento essencial a compreensão da conduta humana dotada de significados. O marco teórico é a Sociologia Compreensiva, que interpreta a ação social como conduta humana dotada de sentido e se desenvolve pela compreensão das ações sociais e do próprio indivíduo como elemento primordial de uma investigação (COHN, 1999, 2003). Para Weber (1994), a compreensão dá-se a partir do sentido que o indivíduo confere a sua participação, com ênfase quando há o compartilhamento de sentido das ações sociais; com a criação de um comportamento reciprocamente referido, surge também a existência da relação social, passível de análise.

Nesse processo, foi utilizada a interpretação teórica de Weber $(1989,1994)$, que estabelece a interpretação da ação social nas diversas formas, a saber: 1) as ações racionais com respeito a um fim, em que o indivíduo tem um objetivo de caráter racional principalmente quanto aos meios que orientam suas ações; 2) as ações racionais com respeito a valores, que se orientam essencialmente por convicções, geralmente tomadas com base nos princípios éticos das pessoas; 3) as ações afetivas que se guiam exclusivamente pelas emoções e pelo sentimento, sem levar em consideração os meios para atingir os objetivos; e as 4) as ações tradicionais que se guiam pelas tradições e costumes e se movem pelo peso do passado.

Utilizou-se uma abordagem qualitativa com a metodologia da história oral, temática, para coletar e identificar os significados atribuídos às condutas da diretora Antonieta, que se inserem na configuração das ações racionais com relação a valores. Assim, as histórias orais reuniram relatos de cinco participantes que contribuíram para o entendimento sobre os significados e demonstram a vinculação das ações da diretora às categorias baseadas em valores de ordem, controle, hierarquia, autoridade, obediência, padrões estéticos e higiênicos. Esses valores faziam parte das convicções de Antonieta, exercidas pelo constante monitoramento, ordenamento e fixação pela aparência física e limpeza do ambiente escolar.

\section{ASPECTOS METODOLÓGICOS E CONTEXTO DA PESQUISA}

Opta-se, neste trabalho, por assumir uma abordagem qualitativa que tem como condição determinante a interpretação do mundo real, com o foco da pesquisa dirigida para a experiência vivida dos seres humanos. Isto é, a investigação qualitativa analisa fenômenos que incorporam experiências subjetivas, mescladas 
aos efeitos nos contextos institucionais e sociais, pois, como afirma Minayo (2001), a pesquisa qualitativa

[...] trabalha com o universo de significados, motivos, aspirações, crenças, valores e atitudes, o que corresponde a um espaço mais profundo das relações, dos processos e dos fenômenos que não podem ser reduzidos à operacionalização de variáveis. (MINAYO, 2001, p. 21-2).

Inicialmente, foi realizado um estudo exploratório com a intenção do conhecimento mais amplo sobre a formação do Ginásio de São Roque no fim da década de 1940 e durante a década de 1950. Nesta pesquisa exploratória, foram realizadas entrevistas livres com moradores, com uma postura de ouvinte, permitindo que essas pessoas de diferentes idades pudessem expressar com maior liberdade suas opiniões sobre o assunto. Tal procedimento seguiu critérios da pesquisa qualitativa que permitem os estudos exploratórios como base de averiguações de um assunto no sentido de proporcionar uma adequada visão geral sobre determinados fatos (TRIVIÑOS, 1987; GIL, 2008).

Deste levantamento, surgiu a confirmação sobre a importância da diretora Antonieta como uma figura central do Ginásio de São Roque. Definiu-se então a necessidade de elucidação adequada dessa personagem, e principalmente, das suas ações sociais desempenhadas.

Partiu-se deste estudo exploratório para a coleta de dados deste trabalho, por meio de entrevistas semiestruturadas com contato mais direto com algumas pessoas que vivenciaram diretamente uma relação com a diretora Antonieta. Nesse contexto, este trabalho entrevistou cinco pessoas consideradas representativas do universo da época, entre elas, estudantes, professores e diretores. Tais pessoas contribuíram para identificar os aspectos significados sobre as ações da diretora Antonieta.

As entrevistas tiveram como orientação os fundamentos metodológicos da história oral. Bom Meihy (1996) explica que a metodologia da história oral conta com três perspectivas expressivas: a de vida, a temática e a de tradição. Neste trabalho, entendeu-se que a perspectiva temática foi a mais adequada ao tema, pois explora as relações entre memória e história e permite entender as relações entre passado e presente. Assim, o passado permanece e é reconstruído segundo a expressão dinâmica do presente, admitindo a subjetividade como uma nova fonte de pesquisa. 
A história oral temática foi muito mais do que apenas outro meio de descobrir fatos sobre o passado, pois se entendeu como uma via metodológica que proporciona a manifestação dos "protagonistas ou testemunhas de acontecimentos e que possibilita a reconstrução da história por meio dos relatos individuais ou coletivos" (ARAGÃO; TIMM; KRETZ2013, p. 35); ou, como afirma Freitas, "essa metodologia abre novas perspectivas para o entendimento do passado recente, pois amplifica vozes que não se fariam ouvir" (FREITAS, 2006, p. 49).

A oralidade narrada do passado, a partir da manifestação do presente, revela-se intensa quando se captam seus significados e conotações, no conteúdo das narrativas, quanto à velocidade, pausa, pontuação e oscilações que se desvelam. Isso significa e pressupõe que o "movimento" contido nas fontes orais permite contar mais com os significados do que o alicerce da escrita normalmente objetivo e estático (PORTELLI, 1997). As pessoas narram acontecimentos já vividos, a partir de seu ponto de vista, com base no momento presente, ou seja, as situações que são motivo das rememorações estão ausentes (LE GOFF, 2003). Nesse sentido, a história oral é muito mais do que apenas outro meio de descobrir fatos sobre o passado, pois as complexidades que surgem do uso das pessoas como nossas fontes dão origem a questões específicas de análise e interpretação.

É uma metodologia criativa e interativa, que força a lidar com muitas camadas de idealizações sobre acontecimentos, contidas nas memórias das pessoas, cujos registros escritos encontram-se, em geral, incompletos ou ausentes, pois, como manifesta Freitas (2006, p. 62), “o discurso oral - natural e espontâneo - é muito mais detalhado e expressivo, ao passo que o discurso escrito é mais formal, elaborado e estereotipado". É nesse sentido que a metodologia da história oral

[...] tem o seu lugar como fonte principal da investigação e envolve um conjunto de entrevistas, que funciona como amostragem significativa, expressiva, pela qual, elementos essenciais do universo em análise devem estar presentes. (SANTOS; ARAUJO, 2007, p. 195).

\section{TRAJETÓRIA DE VIDA DE ANTONIETA DE ARAÚJO CUNHA}

Resgatar elementos da vida de Antonieta de Araújo Cunha foi um processo de descoberta sobre os caminhos, oportunidades e escolhas que foram realizados por ela ao longo de sua trajetória de vida. Tais resgates ofereceram indícios de 
como suas escolhas foram sendo tomadas em sua formação educacional, até os momentos de sua época adulta, com forte relação anterior com sua vida familiar e trazendo subsídios para entender suas escolhas profissionais. Já em uma fase de vida adulta, os percursos percorridos conduziram para sua última atividade profissional na escola em estudo, Ginásio de São Roque.

Antonieta de Araújo Cunha nasceu em 30 de dezembro de 1911, na cidade de São Simão, interior do Estado de São Paulo, filha de Anselmo de Araújo Cunha e Theresa Marroni Cunha (SÃO ROQUE, 2007). O contexto doméstico aponta um núcleo familiar de nove filhos, sendo ela a primogênita dessa família. O falecimento do seu pai, aos 13 anos de idade, trouxe-Ihe um elevado sentido de dever e responsabilidade por toda sua vida (SÃO ROQUE, 2007). Essa perda tornou-se também um desafio familiar, pois passou a representar a necessidade de auxílio ao sustento familiar. Assim, sem o apoio financeiro do pai, com uma família composta por um número grande de pessoas e sendo a primeira filha, suas decisões voltaram-se para a questão da sobrevivência. Tais situações formaram os primeiros indícios que colaboraram para a formação precoce de condições de responsabilização e maturidade que contribuiriam para as ações antecipadas de sua relação com a seriedade da atividade de trabalho. O contexto de busca pelas oportunidades de emprego e suas conduções oportunizou a continuidade dos estudos e a carreira do magistério.

\section{TRAJETÓRIA EDUCACIONAL E PROFISSIONAL DE ANTONIETA DE ARAÚJO CUNHA}

Acredita-se que as escolhas da continuidade dos estudos e da carreira do magistério de Antonieta de Araújo Cunha foram marcadas pela necessidade e pelas demandas de emprego, além da apreciação pessoal pelos estudos, que influenciou as escolhas pela continuidade deles e a carreira do magistério. A decisão familiar pela continuidade do estudo no Ginásio de Ribeirão Preto proporcionou a oportunidade de iniciação da carreira como professora primária em escolas rurais da região de São Simão (SÃO ROQUE, 2007). Na década de 1920, ela ingressou no Ginásio de Ribeirão Preto e seu caminho transcorreu na continuidade dos estudos e na carreira de magistério (SÃO ROQUE, 2007). Durante e após essa formação, Antonieta ministrou aulas como professora primária em escolas rurais do Estado de São Paulo (SÃO ROQUE, 2007). 
Já a década de 1930 foi marcada pela construção de sua carreira de magistério primário em escolas do interior de São Paulo, por meio da realização dos concursos. Assim, Antonieta foi professora primária em Ribeirão Preto entre os anos de 1933 e 1938.

A família de Antonieta mudou-se para a cidade de São Paulo em 1939 e pode-se entender que essa mudança acompanhou a tendência de migração da população do interior do estado para os centros urbanos. No início da década de 1940, Antonieta passou a atuar como professora na capital do estado (SÃO ROQUE, 2007) e, posteriormente, em 1943, trabalhou como professora primária nos grupos escolares das cidades de Altinópolis e Mogi Mirim, escolas no interior do Estado de São Paulo.

No mesmo ano de 1943, suas ações foram marcadas pela realização de curso de Educador Sanitário oferecido pela Faculdade de Higiene e Saúde Pública da Universidade de São Paulo (USP). O curso de Educador Sanitário, entre as décadas de 1920 e 1960, tinha como objetivo capacitar professores para atuação e, com isso, assegurar o entendimento e a necessidade do cuidado com a questão sanitária. A higiene passou a ser o tema principal para atuação nas escolas, como uma função educativa da família. Assim, a escola passou ser o lugar de disseminação de novas condições de saúde, e o trabalho com as crianças foi o meio mais proveitoso de fixação de novos hábitos e costumes (ROCHA; GONDRA, 2002).

Antonieta também buscou sua formação no ensino superior, ingressando no curso de Pedagogia da USP no ano de 1943, graduando-se em 1947 (SÃO ROQUE, 2007). A formação de Antonieta na USP foi marcada pela convivência com o autoritarismo do Estado Novo, entre os anos de 1943 e 1945, e recebeu a influência de eminentes educadores da instituição. Sua formação coincide com o propósito da instituição de que a educação superior tivesse como finalidade a preparação de uma elite à qual caberia a renovação do sistema educativo e o exercício da prática escolar para as massas populares.

Suas experiências profissionais na área do magistério se iniciaram ao longo de seu período de estudos na Escola Normal e continuaram após sua formatura em Pedagogia, no ano de 1947, além do curso de Educador Sanitário. Após sua formação na USP, como professora e educadora sanitária, Antonieta trabalhou na Escola Normal e no Ginásio Estadual de Caçapava, SP, entre 16 de abril de 1948 e 14 de janeiro de 1954. Ela também atuou como psicologista, entre os dias 15 de 
janeiro e 12 de março de 1954, reforçando as relações de formação acadêmica com a prática profissional. Nessa escola, também atuou na área administrativa, ao assumir o cargo de vice-diretora do Ginásio Estadual de Caçapava (VILLAÇA, 1961).

Em 19 de março de 1954, ela foi colocada à disposição do Ginásio Estadual Professor Macedo Soares, na cidade de São Paulo; e, em 31 de janeiro de 1955, ela atuou como diretora no Ginásio Estadual Pedro Brandão dos Reis, na cidade de José Bonifácio; em 7 de março de 1956, foi removida para a Escola Normal e Ginásio Estadual de Itararé, período em que atuou como diretora até 26 de abril de 1958 (VILLAÇA, 1961). Na sequência, Antonieta foi removida por concurso para o ginásio em São Roque, em 25 de abril de 1958². Em 2 de maio de 1958, ela tomou posse como diretora, por um período que totalizou vinte e quatro anos, até sua aposentadoria compulsória, em 6 de janeiro de 1982.

\section{O GINÁSIO DE SÃO ROQUE}

Para entender a relação das ações que foram estabelecidas por Antonieta com o Ginásio de São Roque, resgataram-se informações sobre a situação da escola antes de sua chegada. Assim, a história do Ginásio de São Roque iniciou-se no ano de 1944, com o movimento estabelecido por uma parte da sociedade de São Roque, composta por comerciantes e profissionais autônomos que almejavam uma escola secundária de qualidade para seus filhos. Posteriormente, neste mesmo ano, foi criado um grupo denominado Comissão prol Ginásio, com o objetivo voltado para a sua efetivação. O grupo era composto por dirigentes políticos, comerciantes, professores e membros da sociedade tradicional. Essa comissão inicia os trabalhos de arrecadação financeira, por meio de doações, para a construção do prédio próprio.

A escola foi criada por Decreto-Lei do Estado de São Paulo, n. 16.741, em 17 de janeiro de $1947^{3}$, no contexto da eleição de Adhemar de Barros para o Governo do Estado de São Paulo. No entanto, mesmo após sua criação, a sede própria do ginásio não foi concluída e a escola passou a funcionar no prédio do

\footnotetext{
2 Diário Oficial do Estado de São Paulo, ano LXVIII, n. 90, publicado em 25 de abril de 1958, p. 19.

${ }^{3}$ Diário Oficial do Estado de São Paulo, ano XLII, n. 14, publicado em 18 de janeiro de 1947, p. 3.
} 
Grupo Escolar Bernardino de Campos (GE Bernardino), de forma compartilhada4 . O compartilhamento do edifício perdurou entre os anos de 1947 e 1958.

A utilização compartilhada trouxe prejuízos para a sua estrutura física, além do desgaste emocional no grupo de docentes e discentes de ambas escolas.

A partir da posse da diretora, em maio de 1958, houve um movimento liderado por ela, que demonstra sua forma de agir como diretora do ginásio, com a proposição de criar uma campanha para a conclusão das obras e a mobilização da sociedade local para apoiar a campanha em prol do ginásio (VAMOS..., 1958).

Nesse contexto de incertezas, em julho de 1958, um ato marcante foi coordenado por Antonieta, com o movimento de mudança física do prédio do GE Bernardino de Campos, no centro da cidade, para o prédio em construção, na Avenida João Pessoa. Esse acontecimento representou a mobilização de um grupo de estudantes que levou móveis, livros, equipamentos de laboratório e utensílios para o setor administrativo que estavam armazenados sem a devida utilização, pela ausência do espaço físico apropriado. O ato transcorreu pelas ruas de São Roque, num cortejo a céu aberto, com a ampla participação de alunos e professores, provocando um alvoroço inusitado em toda a cidade.

O grande significado, atribuído a essa conduta, foi a concretização da imagem destemida da nova diretora como liderança ousada e firme na resolução da implantação definitiva da estrutura física do ginásio. Iniciava-se a valorização da nova diretora conquistada ao longo de sua trajetória de ações diante da escola. Ela passou a ser chamada de dona Antonieta, como forma de reconhecimento e de respeito à autoridade.

\section{A ESCOLA DE DONA ANTONIETA}

Na fase de estruturação do Ginásio de São Roque, dona Antonieta incorporou definitivamente os valores da sua época e da importância da sua pessoa. Ela assimilou a legitimidade atribuída às pessoas que governam ou que exercem a gestão, graças à sua qualidade conquistada em ações reconhecidas por uma

\footnotetext{
${ }^{4} \mathrm{O}$ aproveitamento do espaço em outros prédios foi uma decisão governamental utilizada desde 1945 para atender às demandas de bairros populosos da cidade de São Paulo, porém também foi adotado em escolas do interior do estado, na expansão ocorrida durante a década de 1950 (MARCÍlIO, 2005).
} 
comunidade. Por conseguinte, ela também apreendeu o contexto social e político ao qual vivenciava. Sua conduta na fase de estruturação da escola foi apoiada em um paralelo de significados pessoais e sociais, os quais influenciaram todas as suas decisões e ações que seriam desenvolvidas a partir do ano de 1958.

No ano de 1958, Antonieta assumiu a direção do Ginásio de São Roque com uma conduta em prol da construção do prédio do ginásio, como registrado anteriormente, por meio de diversos atos. Sua primeira ação foi a busca do apoio político com o prefeito da cidade para finalização das obras. Wlademir Nardelli ${ }^{5}$ (2019) relata que Antonieta encontrou apoio do prefeito devido à sua habilidade de articulação:

[...] quando ela chegou, não se conformava com a situação que estava lá em cima. Ela caiu na graça do prefeito. Ela logo procurou o prefeito, ela sabia fazer o meio de campo. Eo prefeito era de uma bondade, uma pessoa assim honestíssima, de gabarito das famílias de São Roque, Livio Tagliassachi'. Hoje o acesso tem o nome dele. E caiu nas graças dela e ele topou e falou: vamos continuar as obras do Manley Lane. Ela não pediu autorização para o governo, o governo era outro, Sr. Jânio Quadros, que sucedeu ao Adhemar de Barros, Jânio Quadros. Ela foi e topou. Uma coisa que caiu nas graças do Sr. Lívio foi o seguinte, o pai da dona Antonieta, ele foi maçom em alto grau. (informação verbal).

No segundo semestre de 1958, Antonieta promoveu a mudança do prédio do GE Bernardino de Campos para o prédio do ginásio. Segundo relatos, esse movimento foi um ato coordenado pela própria diretora, que realizou a mudança à revelia do governo estadual, pois o prédio ainda estava em obras. O relato de Neide Schumacker Gomide enfatiza o episódio:

\footnotetext{
${ }^{5}$ Wlademir Nardelli tem origem familiar de descentes de italianos, nascido e residente em São Roque. Estudou no GE Bernardino, fez o ginásio e o colegial em Ciências e Letras em Sorocaba. Durante seu período no colegial, conheceu Antonieta no GE Bernardino e, por sua indicação, trabalhou lecionando nessa escola. Formou-se no ensino superior em História Natural na Faculdade de Filosofia da USP. Lecionou Ciências no Ginásio de São Roque, durante o mandato da diretora Antonieta. Foi supervisor e posteriormente diretor do Ginásio de São Roque, logo após a aposentadoria da diretora Antonieta.

${ }^{6}$ Prefeito da cidade de São Roque entre 1o de janeiro de 1956 e 31 de dezembro de 1956.

${ }^{7}$ Neide Schumacker Gomide formou-se na primeira turma do ginásio, em 1951; foi professora de Português na Escola Estadual Horácio Manley Lane, em 1960, e aposentou em 1986.
} 
Ela ia para São Paulo, ficava na porta dos gabinetes das pessoas que poderiam agir, fazer alguma coisa, fazia cobranças, ia lá, voltava. Sempre muito brava e exigente. Quer dizer, ela cobrava, senão não saía mesmo, né? Depois, quando chegou a construção, não tinha material escolar, os alunos levavam cadeira de casa para a escola funcionar, para não deixar como algumas construções agora, que começam e ficam paradas e não sai do papel. Ela construiu aquele ginásio, o estabelecimento foi muito obra dela, do esforço dela e de todo mundo. (GOMIDE, 2019, informação verbal).

Esse ato teve como objetivo atrair a atenção para a conclusão da obra do ginásio, assim como produzir uma notoriedade da própria diretora, dona Antonieta. Ele se tornaria uma referência marcante pela sua forma de agir e sua personalidade forte, como destacado por uma professora daquela época.

A partir do momento que dona Antonieta assumiu como diretora no novo local do ginásio, iniciou-se a estruturação da escola. Iniciaram-se ações para a criação da Escola Normal, para a formação do magistério. Sua experiência formativa, realizada nos anos de 1930, contribuiu para seu envolvimento na constituição da Escola Normal por meio de sua vivência e influência política para buscar concretizar essa criação.

Após esse momento, a diretora envolveu-se na criação do Instituto de Educação de São Roque, que representava a ampliação da escola para cursos de grau médio, cursos de especialização, de professores e administradores escolares. Assim, no ano de 1960, foi criado o Instituto de Educação em São Roque, pelo governador Carvalho Pinto, pela Lei n. 5.823', de 16 de agosto de 1960.

Os esforços de Antonieta também foram dirigidos para a consolidação do instituto, principalmente na ampliação do corpo docente da escola, na criação do curso primário para o fortalecimento dos estágios dos futuros professores e na criação do ginásio noturno, relatados por Wlademir Nardelli (2019):

Porque ela conseguiu depois, além do científico, nos idos 60, ela conseguiu trazer o ginasial noturno. Foi uma coisa extraordinária, para os alunos que trabalhavam e que vinham de todos os bairros ai de São Roque, de Mairinque, de Alumínio, aqui de Itapevi; vinham para cá, porque não tinha ginásio nos arredores. O ginásio noturno veio graças ao empenho dela, ela tinha muita

\footnotetext{
${ }^{8}$ Lei n. 5.823/60, 16 de agosto de 1960, dispõem sobre a criação de um Instituto de Educação em São Roque. Disponível em: www.al.sp.gov.br/repostitorio/legistacao/lei/1960/lei-582316.08.1960.html
} 
amizade no Departamento de Educação; ela passava até por cima das autoridades lá do palácio, porque ela tinha muita segurança com o pessoal lá do departamento. (informação verbal).

Antonieta estruturou o Instituto de Educação com conhecimento técnico, pautada em sua própria experiência. Em termos práticos, a escola anexa facilitou a realização das atividades complementares da Escola Normal, mas, principalmente, tornou-se elemento atrativo do projeto do curso normal, pois os estudantes permaneciam no ambiente físico da escola, sem a necessidade de busca por estágios em outros lugares.

O Instituto de Educação, em geral, e a Escola Normal, principalmente, proporcionaram maiores oportunidades na carreira de magistério, com formações complementares e iniciação em atividades de trabalho, indicando caminhos para a melhoria de vida e ascensão social de diversas pessoas.

Os anos seguintes, que se estimam a partir de 1967, foram marcados por transformações do número e perfil socioeconômico dos estudantes. Essas mudanças se devem às iniciativas expansionistas implementadas por Ulhoa Cintra no Estado de São Paulo (AZANHA, 2004). Nessas circunstâncias, o Ginásio de São Roque passou de um estado de predominância de estudantes com maior poder socioeconômico, considerados de classe média e alta, para a ampliação de outras classes sociais mais populares. Essa transformação não ocorreu de forma tranquila, como afirma o relato apresentado por Miriam Maluf de Oliveira (2019).

Quem frequentava a escola era um pessoal com mais possibilidade, poder aquisitivo. Quando a escola começou a se abrir, tornava mais popular, para a população em geral, aí a dificuldade dela foi maior. Porque de qualquer forma ela teve que lidar com um outro tipo de aluno, e um aluno que vinha muitas vezes com mais dificuldade para escola. Embora não seja, não dá nem para comparar com hoje. Mas de qualquer forma a escola começou a se modificar. Mas ela não se modificou. Ela se manteve lá naquela escola, do que pode e não pode, o que é permitido, o que não é permitido. Na mesma forma de organização da escola, coisa que ela não conseguiu manter mais. (informação verbal).

Outro momento de transformação ocorreu a partir dos anos 1970. Com a interferência da ditadura civil-militar em quase todos os aspectos políticos e sociais do Brasil, as instituições de ensino tiveram de adotar uma nova orientação, que priorizava o novo ideal da educação de segundo grau direcionado para a formação 
de jovens aptos às ocupações no mercado de trabalho. Assim, em São Roque, no dia 16 de março de 1971, Antonieta iniciou as ações para adaptar a escola aos ajustes do novo ensino de segundo grau e adotar um conjunto de habilitações profissionais nas áreas de ciências contábeis e administrativas; ciências físicas e biológicas; pedagogia; e ciências humanas (ESCOLA HORÁCIO MANLEY LANE, 1949). Antonieta se ajustou ao clima político imperante no país, moldando seu comportamento às novas diretrizes impostas pelo regime militar.

Em 23 de janeiro de 1976, houve a transformação da estrutura do ensino com a oficialização do Instituto Estadual de Educação Horário Manley Lane para Escola Estadual de 1으 e 2o graus Horário Manley Lane. A transformação ocorrida na escola foi sua perda de referência na contribuição e colaboração na formação, principalmente, para a classe média. Antonieta passou a auxiliar na manutenção da ordem escolar para o regime civil-militar, que impunha diretrizes autoritárias, como a maior quantidade de estudantes de diferentes classes sociais.

Até o momento de sua aposentadoria, início do ano de 1982, Antonieta permaneceu administrando situações que ressaltavam sua índole disciplinadora.

\section{A GESTÃO DE DONA ANTONIETA: SIGNIFICADOS E VALORES}

Sumariamente, a diretora Antonieta pode ser considerada como um ícone, ainda que polêmico, dessa escola, pelo seu senso de dever, de dignidade, de ordem e de seus valores morais. Uma representação carregada de significados edificados pelas suas ações corajosas, como a transferência da escola para um prédio ainda em construção, pela busca incessante da conclusão das obras inacabadas, pela preservação contínua da ordem e da limpeza, pela criação dos cursos e a busca contínua por recursos financeiros e equipamentos junto a representantes do poder público municipal e estadual.

Constata-se que Antonieta foi qualificada como a protagonista principal, senão única, da estabilidade dessa escola, pelos seus atos representativos da ousadia, da coragem e do poder de direção e mobilização. Percebem-se essas relações com o relato apresentado a seguir:

Demorou quase um ano para fazer essa mudança. Depois que o governo do estado viu isso. Ela mudou sem ordem do governador e do secretário de Educação. Ela levou uma chamada, uma advertência no Diário Oficial, por descumprir ordem. Mas ela nem ligou. O que ela queria era a comodidade 
dos alunos e um ambiente melhor para trabalhar com os professores né, o espaço... (NARDELLI, 2019, informação verbal, 2019).

A questão de ordem é um elemento central nas ações apresentadas pela diretora. A obrigação e o ordenamento dos estudantes em forma de filas eram frequentes e representavam também as questões da estética, da higiene e da comprovação de organização do uniforme. De acordo com o apresentado no relato de Juarez Pedroso" (2019): "Ela fazia aquela fila assim. Ela ficava lá de pé e olhava todo mundo. Aquele que estivesse cabeludo, aquele que às vezes, no tempo de chuva, molhava o tênis..." (informação verbal).

Ordem, controle e obediência são reflexos do momento histórico do contexto militar do final dos anos 1960 e 1970, que foram assimilados também pelas ações da diretora como elementos favoráveis para a educação na escola. Conforme apresentado por José Roberto Miller ${ }^{10}$ (2019):

E depois a gente não pode esquecer a época em que ela estava lá, né. O período na política, o que passava o Brasil, né. E isso de certa forma influenciou. O autoritarismo, o militarismo. Até posso dizer, não sei se é correto dizer isso? Para entrar, você tinha que fazer fila por série no pátio e subia em fila nos corredores e na escada, até entrar na sala de aula. E ai se alguém saísse da fila. (informação verbal).

O uniforme era uma fixação do exercício administrativo da diretora, que realizava uma supervisão constante sobre os estudantes. A vestimenta, os cabelos e a limpeza serviam para representar a escola em seus elementos estéticos, pois representavam simbolicamente uma escola de qualidade. A padronização dos vestuários, caso do comprimento específico da saia, e dos sapatos, que não podiam ser substituídos por similares, representava a severidade nas expressões comportamentais.

A rigidez com o uniforme, sabe. As moças com saia abaixo do joelho não sei quantos dedos e chegava a coisas assim. Os sapatos dos moços, era necessário eu não lembro se de 3 a 4 furos, para passar o cadarço. Meia. O colarinho de cima abotoado com uma gravata preta fechada. Um calor desgraçado

\footnotetext{
9 Juarez Pedroso foi estudante do Ginásio de São Roque em 1962, expulso da escola em 1963.

10 José Roberto Miller foi estudante do Ginásio de São Roque em 1968, foi professor de História, Geografia e Estudos Sociais na Escola Estadual Horácio Manley Lane, em 1972, filho da inspetora de estudantes Libéria Rabecchini.
} 
e você não podia abrir. Se ela entrasse na sala de aula, e visse o colarinho aberto, era pra fora da sala aos berros. (MILLER, 2019, informação verbal).

O ordenamento também era exercido na manutenção da escola limpa, sem papéis ou objetos jogados no chão. A organização do espaço da escola representava uma questão vital, pois em termos significativos a parte estética e a higienização eram elementos valorizados pela sociedade.

Eu não sei se eu disse. Tinha uma sala de aula que ela arrancou a porta, para poder ouvir barulho na sala dela, se não me engano era sala 8, sabe. E limpeza. Ai se ela visse um papel de bala no chão, ela já gritava. A gente escutava os gritos dela. Pra limpar aquilo lá, olha... e não era sujeira. Às vezes era um papel de bala, uma folha de caderno amassada, alguma coisa assim. Mas era a limpeza do prédio, a ordem do prédio. O jardim tinha que estar impecável, não podia ter um matinho fora do canteiro. Ela era assim, era o prédio, e não os alunos e a parte pedagógica. Era o prédio, a ordem do prédio. (MILLER, 2019, informação verbal).

As ações desenvolvidas pela diretora, que se voltavam prioritariamente para as questões de ordem e limpeza, tinham a colaboração de auxiliares que davam o suporte em questões administrativas e pedagógicas.

E tinha assim esta questão administrativa da escola, né, isso era o que ela fazia, né. A escola tinha uma secretaria, com uma secretária muito competente e uma auxiliar muito competente, e ela confiava neles. Então ela não tinha, vamos assim, o relacionamento com o papel, o andamento, né, era realmente o administrativo da escola, né. Que o aluno não estivesse fora da escola da sala, que a escola estivesse limpa e não estivesse papel no chão, né. Ela gostava de mandar aluno catar papel. (OLIVEIRA, 2019, informação verbal).

Assim como sua chegada, a aposentadoria de Antonieta é recordada como um momento marcante da sua história na escola. A saída foi considerada um alívio para aqueles que não queriam mais as constantes ações de controle. Ao mesmo tempo, foi considerada como um momento de tristeza, pelo fato de ela não aceitar seu desligamento da escola. A continuidade de suas ações, mesmo aposentada, é avaliada como sendo compreensível, tendo em vista que sua vida se voltava exclusivamente para a direção da escola.

Então foi um período assim que eu enxergo como de muito sofrimento para ela, mas muito mesmo, né. E aí você percebia assim, claramente, né, as pessoas que tinham assim um sentimento de 'graças a Deus ela vai embora'. 
Isso acontecia, e o sentimento de quem se compadeceu daquela situação, porque percebia o valor que ela tinha, né, que realmente ela tinha, mais o sofrimento dela. (informação verbal, 2019).

Esses são alguns trechos dos longos relatos que exemplificam um balanço de ações ocorridas no dia a dia da escola, que podem ser entendidas como sendo parte dos valores atribuídos socialmente ao ginásio, mas também representam a força de uma pessoa que tornou uma instituição à sua própria semelhança.

\section{CONCLUSÃO}

Para a Sociologia Compreensiva de Max Weber (1994), o sentido subjetivamente visado passa a ser um componente essencial para a definição de ação. A ação, contudo, não se esgota na simples intencionalidade, pois ela é ação relevante apenas a partir de sua reflexividade, ou seja, quando o sentido composto pela ação se orienta pelo comportamento de outros. Assim, Antonieta construiu suas ações imbuídas por sentidos configurados em sua vida anterior, mas também assimilados e refletidos pelo imaginário coletivo na cidade de São Roque.

Sua ousadia, determinação e coragem foram os elementos centrais enquanto diretora responsável pela estruturação e administração do Ginásio de São Roque. Porém, na perspectiva do referencial de Max Weber, torna-se necessário interpretar a ação social buscando a compreensão por meio da elaboração de causas que possibilitem a decifração do sentido imaginado pelo sujeito da ação.

Nesse sentido, pode-se inferir que Antonieta agia em conformidade com suas próprias conviç̧ões determinadas pela forma que construiu sua vida, como também pela percepção das circunstâncias da comunidade, em relação a uma instituição de ensino. As ações de controle dos estudantes envolviam a ligação e a cumplicidade da escola e das suas famílias. A atenção do aluno que fosse identificado em uma atitude inadequada se iniciava pela identificação do sobrenome, reforçado por ameaças de punição que envolviam o contato com os pais. Ela acreditava na disciplina rígida, na perfeição da aparência física e na limpeza rigorosa do ambiente escolar. Todos esses elementos faziam parte de uma exigência ditada pelo senso de dever, de dignidade, referenciado em suas crenças e valores morais e estéticos.

Na acepção de Max Weber, ao interpretar a ação social, deve-se compreender as conexões e as causas para decifrar o sentido imaginado pelo sujeito da 
ação. Entre as diferentes formas de condução da vida social, conforme exposto antes, Max Weber apresenta diferentes tipos ideais: ação social/racional com relação aos fins, ação social/racional com relação a valores, ação social afetiva e ação social tradicional. Entende-se que Antonieta agia conforme a ação social/ racional com relação a valores, com base em convicções pela obrigação, pelo dever ou por sua própria ética. Suas convicções de vida foram baseadas no senso de responsabilidade de resolução de situações do Ginásio de São Roque e nos valores de organização, ordem e disciplina rígida, elementos que refletiam nas suas ações de monitoramento, organização e perfeição da aparência física e na limpeza rigorosa do ambiente escolar. A representatividade desses valores em sua vida foi tão forte que se pôde perceber que suas ações foram realizadas, conforme expressado pelo autor Max Weber (1989, p. 43), como atos executados "pela importância de uma causa, não importando qual o seu fim". Evidencia-se, deste modo, segundo Lemos (2012, p. 114), que

[...] cabe destacar a figura do agente individual, enquanto entidade portadora de sentido, como responsável por levar suas motivações às ações sociais, as quais são (típico-idealmente falando) de cunho afetivo, tradicional, racional conforme fins ou racional conforme valores.

O fato é que, no "espírito do capitalismo", conforme a expressão de Max Weber (2018), em sua obra máxima "A ética protestante e o novo espírito do capitalismo", os valores são meios instrumentais que definem as relações sociais, favorecem e caracterizam produção de excedentes, gerando o acúmulo de capital. Nesse sentido, Antonieta viveu e propagou uma ética de valores morais voltada a disciplinar comportamentos, sem um fim definido e, o mais importante, em uma cidade ou comunidade que não estava plenamente inserida ou conformada a uma base de interesses da razão prática do mundo capitalista.

Max Weber se refere à racionalização no mundo contemporâneo, tendo em vista a importância crescente das organizações e instituições formais e racionais. Nesse caso, pode-se deduzir que a racionalidade por valores nas ações exercidas por Antonieta estaria compreendida na imposição dos costumes: disciplina, no lugar da indisciplina de hábitos; a limpeza, no lugar da ausência de práticas domésticas; a organização, por ausência de um novo ordenamento político e jurídico. De fato, não houve consonância entre o exercício de ações valorativas, consideradas como racionais pelos fins, em acordo com a crescente organização 
do espaço industrial brasileiro, que se articulava nos grandes centros urbanos; isto é, as ações racionais de valores não obedeceram necessariamente a uma lógica finalística, foram apenas preparatórias ou formativas, mas não utilitaristas, pela simples razão de que os alunos e suas famílias ainda não viviam no ambiente integral de uma forma capitalista de sociabilidade.

A viabilização do ginásio se confundia, de fato, com a herança do período anterior da dominação dos setores agrários, pois, como esclareceu Skidmore (1998, p. 199), "a despeito do rápido crescimento das cidades, mais da metade de todos os brasileiros na década de 1950 ainda vivia no campo", e o que se apresentava no contexto da população da cidade de São Roque era apenas uma percepção, ainda difusa, pela demanda pela educação como oportunidade de um horizonte de desenvolvimento econômico e possibilidades de inserção social por meio da escolarização.

A chegada da ditadura em 1964 transformou o panorama político em todo o país. O perfil de controle, comando e hierarquia associados à própria concepção militarista se ajustou adequadamente aos padrões morais e comportamentais administrativos rígidos da diretora Antonieta. Não se pode dizer, no entanto, que o modo de agir dela foi alterado a partir das mudanças dos contextos políticos desse triste momento histórico. Sua índole e seu perfil de atuação tinham sido moldados ao longo dos anos de sua trajetória de vida e por concepções apreendidas competentemente no coletivo de suas vivências. No entanto é evidente que o clima político militarista fortaleceu as ações da autoridade de Antonieta, desde o momento do golpe de 1964, até sua melancólica aposentadoria, em 1982.

O ginásio foi, ao longo das décadas de 1960 e 1970, moldado pela diretora para ser uma escola reconhecida socialmente pelos padrões sociais de uma educação rígida, da prioridade da higiene e limpeza e de controle das ações estudantis. A escola de dona Antonieta era considerada uma instituição de qualidade e excelência, muito bem conceituada na cidade. Essa premissa foi constatada pelo imaginário que se consolidou, ao longo do tempo, na cidade de São Roque, tendo como base um saudosismo de momentos considerados como os melhores dessa escola. Considerados como os anos dourados do ginásio, esses momentos representaram uma relação de existência dependente da diretora, que dedicou tempo e exercício em ações fortes, organizativas e controversas. No 
entanto há variações nas posições em relação a sua forma de agir, ser e pensar, tendo como base percepções diferenciadas sobre a pessoa Antonieta e a diretora dona Antonieta.

É nesse sentido que se pode afirmar que, para a pessoa Antonieta, a responsabilidade sobre a escola foi inteiramente inserida em sua vida, ocupando a centralidade de todas as suas ações. Tal situação se transformou em uma obstinação, pois dedicou sua vida a essa causa, desistindo de ter um núcleo familiar próprio. Assim, ao se aposentar, ela manteve suas vinculações, indo morar numa casa em frente à escola, exercendo constantemente um comportamento de vigilância e controle nas formas organizativas da instituição.

Assim, dona Antonieta foi uma personagem marcante em sua época, um ícone, pois, acima de tudo, ela se negou a desempenhar o personagem de uma mulher infligida pela irrelevância no desempenho de uma direção escolar.

\section{REFERÊNCIAS}

ARAGÃO, Milena; TIMM, Jordana Wruck; KRETZ, Lúcio. A história oral e suas contribuições para o estudo das culturas escolares. Conjectura: Filosofia e Educação, Caxias do Sul, RS, v. 18, n. 2, p. 28-41, maio/ago. 2013.

AZANHA, José Mario Pires. Democratização do ensino: vicissitudes da ideia no ensino paulista. Revista Educação e Pesquisa, São Paulo, v. 30, n. 2, p. 335-44, maio/ago. 2004.

BOM MEIHY, José Carlos Sebe. Manual de história oral. São Paulo: Edições Loyola, 1996.

COHN, Gabriel. Crítica e resignação: Max Weber e a teoria social. 2. ed. São Paulo: Martins Fontes, 2003.

COHN, Gabriel. Max Weber: a "objetividade" do conhecimento nas ciências sociais. São Paulo: Ática, 1999.

ESCOLA ESTADUAL HORÁRIO MANLEY LANE (São Roque). Livro do histórico do estabelecimento [Documento Oficial]. São Roque, SP, 1949. p. 57.

FREITAS, Sônia Maria de. História oral: possibilidades e procedimentos. 2. ed. São Paulo: Associação Editorial Humanitas, 2006.

GIL, Antonio Carlos. Métodos e técnicas de pesquisa social. 6. ed. São Paulo: Atlas, 2008. 
GOMIDE, Neidi Schumacker. Entrevista oral [cedida a] Tarina Unzer Macedo Lenk. São Roque, SP, jan. 2019.

LE GOFF, Jacques. História e memória. 5. ed. Campinas, SP: Unicamp, 2003.

LEMOS, Marcelo Rodrigues. Estratificação social na teoria de Max Weber: considerações em torno do tema. Revista lluminart, Florianópolis, ano IV, n. 9, p. 113-27, nov. 2012.

MARCÍLIO, Maria Luiza. História da Escola em São Paulo e no Brasil. São Paulo: Imprensa Oficial do Estado de São Paulo, 2005.

MILLER, José Roberto. Entrevista oral [cedida a] Tarina Unzer Macedo Lenk. São Roque, SP, fev. 2019.

MINAYO, Maria Cecília de Souza (Org.). Pesquisa social. Teoria, método e criatividade. 18. ed. Petrópolis, RJ: Vozes, 2001.

NARDELLI, Wlademir. Entrevista oral [cedida a] Tarina Unzer Macedo Lenk. São Roque, SP, jan. 2019.

OLIVEIRA, Miriam Maluf. Entrevista oral [cedida a] Tarina Unzer Macedo Lenk. São Roque, SP, jan. 2019.

PEDROSO, Juarez. Entrevista oral [cedida a] Tarina Unzer Macedo Lenk. São Roque, SP, fev. 2019.

PORTELLI, Alessandro. O que faz a história oral diferente. Revista do Programa de Estudos Pós-Graduação em História, São Paulo, n. 14, p. 25-39, fev. 1997.

ROCHA, Heloísa Helena Pimenta; GONDRA, José Gonçalves. A escola e a produção de sujeitos higienizados. Perspectiva, Florianópolis, v. 20, n. 2, p. 493-512, jul./dez. 2002.

SANTOS, Maria dos Santos; ARAUJO, Osmar Ribeiro de. História oral: vozes, narrativas e textos. Cadernos de História da Educação, Uberlândia, MG, n. 6, p. 191-201, jan./dez. 2007.

SÃO ROQUE [Município]. Lei n. 00057/2007-L, de 13 de julho de 2007. Denominação da escola municipal Professora Antonieta de Araújo Cunha Laurenciano. São Roque, SP: Câmara Municipal, [2007]. Disponível em: https://consulta.siscam.com.br/ camarasaoroque/Documentos/Documento/52740. Acesso em: 11 maio 2020.

SKIDMORE, Thomas E. Uma história do Brasil. São Paulo: Paz e Terra, 1998. 
TRIVIÑOS, Augusto Nibaldo Silva. Introdução à pesquisa em ciências sociais: a pesquisa qualitativa em educação. São Paulo: Atlas, 1987.

VAMOS concluir as obras do colégio. O Democrata, São Roque, SP, ano 42, n. 2112, p. 4, 10 maio 1958.

VILLAÇA, Ivaldo. Certidão sobre a formação acadêmica e carreira profissional da Sra. Antonieta de Araújo Cunha. São Roque, SP: Secretaria de Estado dos Negócios da Educação, Departamento de Educação, Instituto de Educação Horácio Manley Lane, 1961.

WEBER, Max. A ética protestante e o espirito do capitalismo. Lisboa: Relógio D’Água Editores, 2018.

WEBER; Max. Economia e sociedade: fundamentos da sociologia compreensiva. 3. ed. Brasília: Editora da Universidade de Brasília, 1994.

WEBER; Max. Conceitos básicos de sociologia. Tradução Gerard Georges Delaunay, Rubens Eduardo Ferreira Frias. São Paulo: Editora Moraes, 1989.

\section{Sobre os autores:}

Tarina Unzer Lenk: Doutora em Educação pela Universidade de Sorocaba (UNISO). Professora Adjunta do Instituto Federal de São Paulo e Universidade Federal do Vale do São Francisco. E-mail: tarinalenk@gmail.com, Orcid: http://orcid.org/0000-0002-1681-7555

Wilson Sandano: Doutor em Educação pela Universidade Metodista de Piracicaba (UNIMEP). Professor Titular do Programa de Pós-Graduação da Universidade de Sorocaba (UNISO). E-mail: wilsonsandano@uol.com.br, Orcid: https://orcid.org/0000-0001-9587-3733

\section{Recebido em 15 de dezembro de 2019. Aprovado em 20 de maio de 2020.}


